\title{
Gross Morphometrical Studies on the Femur of Chital (Axis axis)
}

\author{
Md. Mofijul Islam*, Dharmendra Singh and Avnish Kumar Gautam \\ Department of Veterinary Anatomy and Histology, Faculty of Veterinary and Animal Sciences \\ West Bengal University of Animal and Fisheries Science, Kolkata-37, India \\ *Corresponding author
}

\begin{abstract}
A B S T R A C T
Keywords

Chital, Femur,

Morphometry,

Gross

\section{Article Info}

Accepted:

26 May 2018

Available Online:

10 June 2018

The study was conducted on the femur of four spotted deer. The femur had an average length of $22.4 \mathrm{~cm}$ and its cylindrical shaft was curved cranially at the middle and distal third of bone. The nutrient foramen is present on the proximal third of cranial surface. The caudal surface had a prominent lateral femoral lip and a developed supra condyloid fossa. The proximal extremity was consisted a medially placed head, greater trochanter and minor trochanter. On the caudomedial aspect of head, a shallow fovea capitis was observed. The lateral and medial condyles of distal extremity had average length and breadth of $5.1 \mathrm{~cm}$ and $2.8 \mathrm{~cm} ; 4.7 \mathrm{~cm}$ and $2.0 \mathrm{~cm}$ respectively. The summit of greater trochanter was placed in the level with the head. The length and breadth of trochlear groove was $5.2 \mathrm{~cm}$ and $2.4 \mathrm{~cm}$ respectively. The medial trochlear ridge was more prominent than the lateral one.
\end{abstract}

\section{Introduction}

The chital or spotted deer is found in the Indian subcontinent and prefer dense deciduous forests, semi-evergreen forests and open grasslands. They are herbivorous ruminants and feed on various type grasses, herbs, shrubs, leaves, fruits and branches of trees. The chital or spotted deer protected under Schedule - III, according to wildlife (Protection) act, 1972 and classified as Least Concern (LC) by the IUCN. Femur is largest and strongest bone which act as supporting lever and for the forward propulsion of the body (Rajaniet.al. 2012). The aim of this study is to reveal the description of femur of the spotted deer, thereby making a contribution in filling the gap of knowledge in this field. As per knowledge, in many vetero-legal cases one fails to identify the bones of this animal and confuse them with those of some other small ruminants. This investigation will be helpful to the field veterinarians as well as zoo veterinarians.

\section{Materials and Methods}

The samples were collected from four spotted deer(chital) died due to natural cause at Alipore Zoological Garden, Kolkata, after permission with zoo authorities. Bones were processed for studying the gross 
morphological and morphometrical features (Raghavan, 1964).The gross studies were carried out at department of Veterinary Anatomy and Histology, West Bengal University of animal and fisheries science, Kolkata. The present investigation were undertaken with several morphometrical parameters like length of bone, shaft circumferences, condyle length, length and breadth of trochlear groove and head circumferences. The measurement was done with vernier calipers, silk thread and measuring scale.

\section{Results and Discussion}

The femur was largest bone which comprised of a slender shaft, proximal extremity and distal extremity (Fig.1). The average length of femur was $22.4 \mathrm{~cm}$. The shaft was cylindrical in the middle and prismatic distally. The Anterior, medial and lateral surface were continuous and smooth. The anterior surface had a nutrient foramen on the proximal third of bone (Rajaniet.al. 2012). The posterior surface was flattened and on the middle of this surface facies aspera was present for the attachment of adductor muscles. It is delimited by prominent lateral femoral lip which continued up to greater trochanter and medial femoral lip was ill developed and terminated immediately (Fig.2). This finding is agreed with Getty (1975) in small ruminants.

The shaft was slightly curved cranially at middle and distal part of bone which agreed with Nickel et.al (1986) in small ruminants. The shaft had an average circumference of $8.2 \mathrm{~cm}, 7.2 \mathrm{~cm}$ and $7.6 \mathrm{~cm}$ at the proximal, middle and distal third respectively. A welldeveloped supracondyloid fossa was present between the lateral femoral lip and lateral epicondyle at distal end on the posterior surface of shaft (Nickel et.al., 1986).

Fig.1 Gross photograph of anterior view of femur showing shaft (S), proximal extremity (P), distal extremity (D) and trochlear groove (TG)

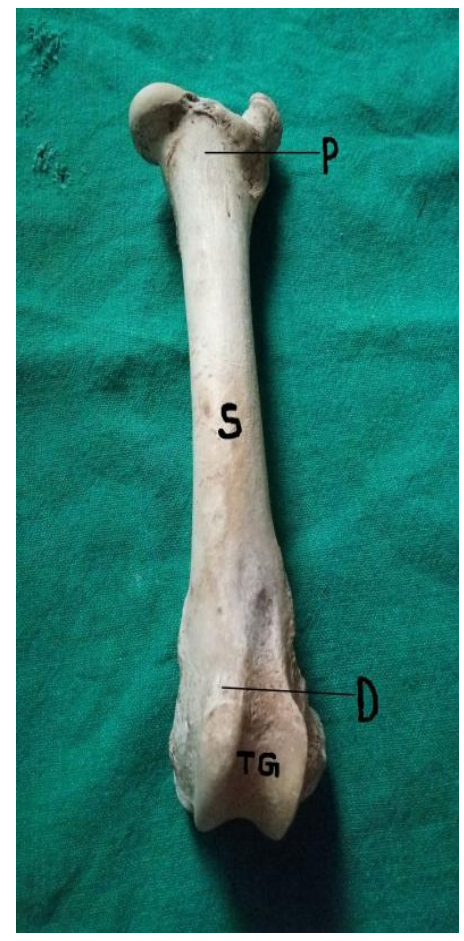


Fig.2 Gross photograph of posterio- medial aspect of femur showing greater trochanter (GT), head (H), neck(N), minor trochanter (MT),facies aspera (FA),supracondyloid fossa (SF), lateral condyle (LC), medial condyle (MC) and inter condyloid fossa (IF)

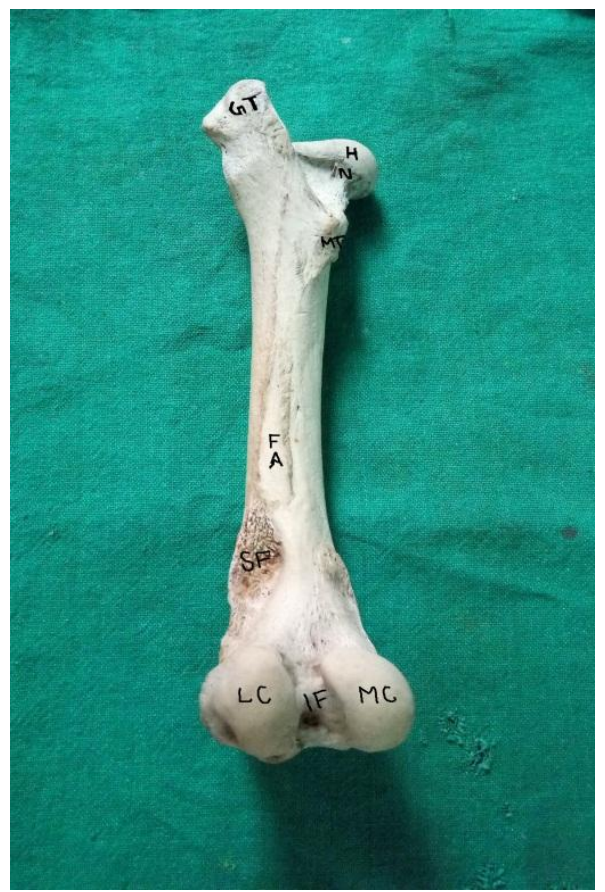

The Proximal extremity comprises head, neck and two trochanter (Fig.2). The rounded head projected more medially as in small ruminants (Nickel et al., 1986). The average head circumferences was $9.2 \mathrm{~cm}$. A shallow fovea capitis was situated posterio-medially on the head for the attachment of the round ligament. The neck was distinct as in small ruminants (Dyce et al., 1996). On the proximal extremity just lateral to the head there was undivided trochanter major and its summit was placed almost in level with that of the head as reported by (Rajaniet.al. 2012) in sambar deer. But this finding disagrees with Nickel et al., (1986) who stated that in large ruminants the greater trochanter was located at a higher level than the head. The medial surface of the greater trochanter was excavated into a deep trochanteric fossa. The shaft presented a small protuberance, the trochanter minor at the proximal third of its posterior medial aspect. The inter trochanteric crest was very well developed (Fig.2).
The distal extremity comprises caudally projected two large condyles and acranial trochlea (Fig.). The average length and breadth of lateral and medial condyles were $5.2 \mathrm{~cm}$ and $2.8 \mathrm{~cm} ; 4.7 \mathrm{~cm}$ and $2.0 \mathrm{~cm}$ respectively. Between the two condyles, anoblique, rough inter-condyloid fossa was present as in small ruminants (Nickel et al., 1986). The smooth wide trochlear groove had a length of $5.1 \mathrm{~cm}$ and breadth of $2.4 \mathrm{~cm}$.

It was bounded by two parallel sagittal slightly oblique ridges i.e. medial and lateral. The former one was more prominent. This observation is similar to that of large ruminants where the medial ridge is more prominent and disagrees with small ruminants where both ridges are equal (Getty, 1975; Nickel et al., 1986). The lateral condyle showed deep extens or fossa and shallow popliteal fossa (Rajani et al., 2012). 


\section{References}

Dyce, K.M., Sack, W.O. and Wensing, C.J.G. (1996). Textbook of Veterinary Anatomy, 2nd edn, WB Saunders Company, Philadelphia. pp: 88-89.

Getty, R. (1975). Sisson and Grossman's The Anatomy of The Domestic Animals Vol II $5^{\text {th }}$ edn WB Saunders Company, Philadelphia. pp:758-759,778.

Nickel, R., Schummer, A. and Seiferle, E. (1986). The locomotor system of domestic mammals. Verlag Paul Parey, Berlin, Hamburg. pp:83-85,95. Raghavan, D. (1964). Anatomy of the ox. Indian Council of Agricultural Research. New Delhi.

Rajani, C.V; Raj, S; Chandrasekhar, L; Maya, S; Pradeep, M and Sajitha, I.S. (2012). Morphological Studies on the femur and patella of Sambar Deer. Tamilnadu. J. Veterinary \& Animal sciences 8(1)19-21, January-February issue.

\section{How to cite this article:}

Md. Mofijul Islam, Dharmendra Singh and Avnish Kumar Gautam. 2018. Gross Morphometrical Studies on the Femur of Chital (Axis axis). Int.J.Curr.Microbiol.App.Sci. 7(06): 3582-3585.

doi: https://doi.org/10.20546/ijcmas.2018.706.421 